\title{
A Non-Ergodic Ground-Motion Model of Fourier Amplitude Spectra for France
}

Chih-Hsuan Sung ( $\square$ karensung@berkeley.edu )

UC Berkeley: University of California Berkeley https://orcid.org/0000-0001-7606-0366

Norman Abrahamson

UC Berkeley: University of California Berkeley

Nicolas M. Kuehn

UC Los Angeles: University of California Los Angeles

Paola Traversa

EDF Lab Saclay

Irmela Zentner

EDF Lab Saclay

\section{Research Article}

Keywords: Non-ergodic GMMs, PSHA, FAS, France

Posted Date: August 17th, 2021

DOl: https://doi.org/10.21203/rs.3.rs-358937/v1

License: (c) (1) This work is licensed under a Creative Commons Attribution 4.0 International License.

Read Full License 


\section{A Non-ergodic Ground-motion Model of Fourier Amplitude Spectra 2 for France}

4 Chih-Hsuan Sung1 • Norman A. Abrahamson*1 • Nicolas M. Kuehn² • Paola Traversa ${ }^{3} \bullet$

5 Irmela Zentner ${ }^{4}$

8 Abstract We used an ergodic ground-motion model (GMM) of California of Bayless and Abrahamson (Bull 9 Seismol Soc Am 109(5):2088-2105, 2019) as a backbone model and incorporated the varying-coefficient model 10 (VCM), with a modification for anisotropic path effects, to develop a new non-ergodic GMM for France based on 11 the French RESIF data set (1996-2016). Most of the earthquakes in this database have small-to-moderate 12 magnitudes (M2.0 - M5.2). We developed the GMM for the smoothed effective amplitude spectrum (EAS) rather 13 than for elastic spectral acceleration because it allows the use of small magnitude data to constrain linear effects of 14 the path and site without the complication of the scaling being affected by differences in the response spectral shape. 15 For the VCM, the coefficients of GMM can vary by geographical location and they are estimated using Gaussian16 process regression. There is a separate set of coefficients for each source and site coordinate, including both the 17 mean coefficients and the epistemic uncertainty in the coefficients. We further modify the anelastic attenuation term of a GMM by the cell-specific approach of Kuehn et al. (Bull Seismol Soc Am 109 (2): 575-585, 2019) to allow for azimuth-dependent attenuation for each source which reduces the standard deviation of the residuals at long distances. As an example, we compute the $5 \mathrm{~Hz}$ seismic hazard for two sites using the non-ergodic EAS GMM. At the $1 \times 10^{-4}$ annual frequency of exceedance hazard level, there can be a large difference between the ergodic hazard and the non-ergodic hazard if the site is close to the available data. The combination of the non-ergodic median ground motion and the reduced aleatory variability can have large implications for seismic-hazard estimation for long return periods. For some sites, the estimated hazard will increase and for other sites the estimated hazard will decrease compared to the traditional ergodic GMM approach. Due to the skewed distribution of the epistemic uncertainty of the hazard, more of the sites will see a decrease in the mean hazard mean hazard at the $1 \times 10^{-4}$ hazard level than will see an increase as a result of using the non-ergodic GMM.

1 Department of Civil and Environmental Engineering, University of California, Berkeley

2 B. John Garrick Institute for the Risk Sciences University of California, Los Angeles

3 EDF-DIPNN-DI-TEGG, Aix-en-Provence, France

4 Électricité de France, EDF R\&D, Lab Saclay, France 


\section{Introduction}

40 The results of probabilistic seismic hazard analysis (PSHA) are sensitive to the standard deviation (also called sigma)

41 for empirical ground-motion models (GMMs); even small reductions in sigma may have a significant impact on the

42 hazard at long return periods (Bommer and Abrahamson 2006). As ground-motion data sets have grown over the

43 past decade, there has been a trend of moving from ergodic to non-ergodic GMMs. The 2008 Next Generation

44 Attenuation-West1 (NGA-W1) GMMs developed for crustal earthquakes (Power et al. 2008) were fully ergodic

45 models that were applied to all regions within the same broad tectonic category. Six years later, with a much larger

46 data set available, four of the 2014 Next Generation Attenuation-West2 (NGA-W2) GMMs for crustal earthquakes

47 (Abrahamson et al. 2014; Boore et al. 2014; Campbell and Bozorgnia 2014; Chiou and Youngs 2014) included

48 regional differences in four terms of the GMMs: constant term, large distance scaling, the $\mathrm{V}_{\mathrm{S} 30} \mathrm{scaling}$, and the basin

49 depth scaling. Within broad regions, there are still regional differences in the median ground motion on a scale of

$5010 \mathrm{~s}$ of $\mathrm{km}$. This has led to the development of non-ergodic GMMs in which the median ground motion depends on

51 the coordinates of the source and the site.

52 Non-ergodic GMMs have a significantly smaller aleatory variability compared to ergodic GMMs. This 53 reduction in the aleatory variability has been seen in many studies (Atkinson 2006; Anderson and Uchiyama 2011;

54 Lin et al. 2011; Rodriguez-Marek et al. 2013; Kotha et al. 2016; Lanzano et al. 2017; Sung and Lee 2019) with

55 different data sets, and have shown that for a specific site and earthquake pair, the variance of the aleatory variability

56 is only $30-40 \%$ of the ergodic variance, indicating that most of the variability treated as randomness in ergodic

57 GMMs is actually due to systematic source, path, and site effects. A partially non-ergodic approach (called single-

58 station sigma) that only accounts for the systematic site terms has been used in seismic hazard studies for nuclear

59 power plants and dams over the past ten years (e.g., Renault et al. 2010; BCHydro 2012; Coppersmith et al. 2014;

60 Bommer et al. 2015; Geopentech 2015; Tromans et al. 2019). A fully non-ergodic GMM for California was

61 developed by Abrahamson et al. (2019) by combining the varying-coefficient model (VCM) of Landwehr et al.

62 (2016) with the cell-specific approach (Kuehn et al.2019). Fully non-ergodic GMMs have not yet been used for

63 projects, but as these models begin to be applied, there will be significant changes in the hazard for sites with nearby

64 data (earthquakes and recording stations). For sites without nearby data, there will be no change in the mean hazard 65 as compared to the ergodic hazard, but there will be larger epistemic uncertainty in the hazard.

66 Most GMMs for engineering applications are developed for 5\%-damped pseudospectral acceleration (PSA); 67 however, PSA scaling depends on the spectral shape, so the linear source, path, and site effects will not have the 68 same scaling on the PSA values for small and large magnitudes. In contrast, the Fourier transform is a linear operator 69 so linear effects from small magnitudes can be applied to larger magnitudes. Therefore, the non-ergodic model is 70 developed for the Fourier amplitude spectra (FAS) values rather than for the PSA values. Developing the GMM for 71 FAS as the added advantage that it is easier to constrain the extrapolation of the GMM using the seismological 72 theory for ground-motion scaling (Brune 1970; Boore et al. 2014) and can provide more useful constraints for the 73 input parameters of finite-fault simulations.

74 In this paper, we summarize the EAS ground-motion model developed by Sung and Abrahamson (2020) 
75 (called SA20), including the selection of the ground-motion data, the basis for the French ergodic model, and the 76 incorporation of the non-ergodic terms to develop a fully non-ergodic GMM for France including epistemic 77 uncertainty. In the final section, we show an example seismic hazard analysis for 5-Hz PSA and compare the nonergodic hazard with the results using a traditional ergodic GMM.

\section{Data sets}

80 We used the processed ground-motion data from the Réseau Sismologique et géodésique Français (RESIF) data set, 81 which includes more than 6500 recordings from 468 earthquakes recorded at 379 stations in Metropolitan France 82 between 1996 and 2016. This dataset contains data recorded by accelerometric and broadband sensors (RESIF 1995) 83 and is available as a version-numbered flat file containing the metadata, the response spectra for several damping 84 values, and the Fourier amplitude spectra (Traversa et al. 2020). Two methods for the conversion to moment magnitude were used based on the year of the earthquake: for the earthquakes that occurred in France between 1996 to 2009 , the moment magnitudes was provided by the Sismicité Instrumentale de l'Hexagone (Si-Hex) project (Cara et al. 2015); for earthquakes that occurred after 2009, the moment magnitude was estimated using the conversion equation proposed by Grunthal et al. (2009) (Bremaud and Traversa 2019).

Fig. 1 shows a map with the event and station locations in the data set that were selected. For the groundmotion model, the site conditions are parameterized by the time-averaged shear-wave velocity over the top 30 meters $\left(\mathrm{V}_{\mathrm{S} 30}\right)$; however, $\mathrm{V}_{\mathrm{S} 30}$ measurements are not available for about one-half of the recordings in the RESIF data set. For the stations without measured $\mathrm{V}_{\mathrm{S} 30}$, we used the estimates from the global $\mathrm{V}_{\mathrm{S} 30}$ map of the United States Geological Survey (USGS) which uses the topographic slope as a proxy for the $\mathrm{V}_{\mathrm{S} 30}$ (Wald and Allen 2007; Allen and Wald 2009). As we will estimate the site-specific site terms as part of the development of the non-ergodic GMM, using proxies for the for $\mathrm{V}_{\mathrm{S} 30}$ is not a key limitation of the study because the non-ergodic site terms will account for errors in estimated $V_{S 30}$. The final subset consists of 6044 recordings from 463 earthquakes with the range of moment magnitude $(\mathbf{M})$ between 2.0 to 5.2, rupture distance $\left(\mathrm{R}_{\mathrm{RUP}}\right)$ between $2 \mathrm{~km}$ to $660 \mathrm{~km}$, and $\mathrm{V}_{\mathrm{S} 30}$ is between 171 to $3100 \mathrm{~m} / \mathrm{s}$ (Fig. 2). The usable frequency band was set based on the filters applied during the data processing.

The intensity measured used in the ground-motion model is the "Effective Amplitude Spectrum" (EAS) defined by Goulet et al. (2018). The EAS is an orientation-independent measure of the average horizontalcomponent FAS of the ground acceleration. The EAS is smoothed over a frequency band using the $\log _{10}$-scale Konno and Ohmachi (1998) smoothing window with weights defined as follows:

$$
W(f)=\left(\frac{\sin \left(b \log \left(f / f_{1}\right)\right.}{b \log \left(f / f_{1}\right)}\right)^{4}
$$

104 in which $\mathrm{f}_{1}$ is the center frequency of the window, $\mathrm{b}$ is the window parameter $\left(=2 \pi / b_{w}\right)$ and $\mathrm{b}_{\mathrm{w}}$ is a smoothing 105 parameter. The Konno and Ohmachi smoothing window was selected for use in PEER projects because it led to 106 minimal bias on the amplitudes of the smoothed EAS compared with the unsmoothed EAS. The PEER procedure uses $b_{w}=0.0333$ for the smoothing parameter because it leads to a minimal effect on the statistical moments of the EAS that are used in RVT to convert the EAS model to a response spectrum model. 


\subsection{Ergodic EAS ground-motion model}

111 The ergodic EAS model for France is based on a simplified form of the Bayless and Abrahamson (2019) empirical 112 EAS GMM for shallow crustal earthquakes in California (called BA19). The magnitude scaling in the BA19 113 functional form is based on the functional form used in the Chiou and Youngs (2014) GMM (called CY14) for 114 response spectral values. The advantage of this form is that it is consistent with the magnitude scaling of FAS from 115 small to large magnitudes (M3-M8). The functional form used for the French ergodic GMM includes the magnitude scaling, path scaling, linear site amplification, and depth to the top of the rupture $\left(\mathrm{Z}_{\mathrm{TOR}}\right)$ scaling as shown in eq. 2 :

$$
\ln \left(E A S_{e s}\right)=c_{1}+c_{2}(\mathbf{M}-6)+c_{3} \ln \left(1+e^{c_{n}\left(c_{M}-\mathbf{M}\right)}\right)+c_{4} \ln \left(R_{\text {rup }}+c_{5} \cosh \left(c_{6} \max \left(\mathbf{M}-c_{h m}, 0\right)\right)\right)+(-0.5-
$$

$$
\left.c_{4}\right) \ln \left(\sqrt{R_{\text {rup }}^{2}+c_{R B}^{2}}\right)+c_{7} R_{\text {rup }}+c_{8} \ln \left(\min \left(V_{S 30}, 1000\right) / 1000\right)+c_{9} \min \left(Z_{\text {tor }}, 20\right)+\varepsilon_{\text {es }}
$$

in which $\mathbf{M}$ is the moment magnitude; $R_{r u p}$ is the shortest distance from the site to the rupture plane in $\mathrm{km} ; c_{R B}$ is the midpoint of the transition in distance scaling; $\mathrm{V}_{\mathrm{S} 30}$ is in $\mathrm{m} / \mathrm{s} ; Z_{\text {tor }}$ is the depth to the top of the rupture plane in $\mathrm{km} ; \varepsilon_{e s}$ is the total residual in nature logarithm unit for earthquake $e$ and station $s$. For the French ground-motion data set, the EAS are not reliable at long periods ( $\mathrm{T}>1 \mathrm{sec})$, and the amplitudes are in the linear range, so the basindepth scaling and the non-linear site effects in the BA19 functional form are not included. Because there are no data from large magnitude earthquakes in France, the coefficients of the large magnitude scaling for the French ergodic GMM $\left(c_{2}, c_{5}, c_{6}, c_{n}\right.$, and $\left.c_{h m}\right)$ are constrained to the values for the BA19 model. The 12 resulting ergodic model coefficients from $0.1 \mathrm{~Hz}$ to $23.5 \mathrm{~Hz}$ are listed in Table 1 .

In the regression, we used the maximum-likelihood technique based on the random-effects approach (Abrahamson and Youngs 1992) to estimate the coefficients for the ergodic GMM in the statistical software R (Pinheiro et al. 2020). This procedure leads to the separation of total residuals into between-event residuals, between-site residuals, and within-site residuals (Al-Atik et al. 2010). The coefficients are only estimated for frequencies greater than or equal to $1 \mathrm{~Hz}$ is because of the number of useable recordings decays quickly for frequencies less than $1 \mathrm{~Hz}$.

\subsection{Non-ergodic EAS ground-motion model}

Using the notation of Al-Atik et al. (2010), the median non-ergodic GMM can be written as

$$
\mu_{\text {nonerg }}\left(\mathbf{x}, \mathbf{t}_{\mathbf{e}}, \mathbf{t}_{\mathbf{s}}\right)=\mu_{\text {erg }}(\mathbf{M}, \mathbf{R}, \mathbf{S}, \ldots)+\delta L 2 L\left(\mathbf{t}_{\mathbf{e}}\right)+\delta S 2 S\left(\mathbf{t}_{\mathbf{s}}\right)+\delta P 2 P\left(\mathbf{t}_{\mathbf{e}}, \mathbf{t}_{\mathbf{s}}\right) .
$$

in which $\mu_{e r g}(\bullet)$ is the ground-motion relation of the ergodic model with a vector of predictors which includes the earthquake magnitude $(\mathbf{M})$, source-to-site distance $(\mathbf{R})$, and other conditions $(\mathbf{S}), \mathbf{t}_{\mathbf{e}}$ and $\mathbf{t}_{\mathbf{s}}$ are the coordinates of the earthquake and the site, respectively, $\delta L 2 L\left(\mathbf{t}_{\mathbf{e}}\right)$ is adjustment for the source term based on the coordinates of earthquake source location, $\delta S 2 S\left(\mathbf{t}_{\mathbf{s}}\right)$ is adjustment for the site term based on the coordinates of site location, and $\delta P 2 P\left(\mathbf{t}_{\mathbf{e}}, \mathbf{t}_{\mathbf{s}}\right)$ is the path term.

We relate the non-ergodic terms in eq. 3 to the notation of Landwehr et al. (2016) with modifications for the anisotropic linear R scaling used by Abrahamson et al. (2019):

$$
\begin{aligned}
& \delta L 2 L\left(\mathbf{t}_{\mathbf{e}}\right)=\beta_{-1}\left(\mathbf{t}_{\mathbf{e}}\right) \\
& \delta \mathrm{S} 2 \mathrm{~S}_{\mathrm{S}}=\beta_{0}\left(\mathbf{t}_{\mathbf{s}}\right)+f_{V S 30}\left(V s 30 ; \mathbf{t}_{\mathbf{s}}\right)+\delta \mathrm{S}_{\mathrm{S} 2 \mathrm{~S}}^{\prime}
\end{aligned}
$$




$$
\delta P 2 P\left(\mathbf{t}_{\mathbf{e}}, \mathbf{t}_{\mathbf{s}}\right)=\sum_{i}^{N c} \theta_{A t t n, i} \Delta R_{R u p, i}-\theta_{A t t n} R_{R u p}
$$

There are two constants for the constant term, one is correlated $\left(\beta_{0}\left(\mathbf{t}_{\mathbf{s}}\right)\right)$, and another is uncorrelated $\left(\delta \mathrm{S}_{\mathrm{S} 2 \mathrm{~S}}^{\prime}\right)$. There is a spatially correlated change in the $\mathrm{V}_{\mathrm{S} 30}$ scaling term based on the coordinates of site location, $\beta_{4}\left(\mathbf{t}_{\mathbf{s}}\right)$. The $\Delta R_{R u p, i}$ is the length of the ray path from the source to the site in the $\mathrm{i}^{\text {th }}$ cell (Fig. 3). In the reference ergodic GMM, the linear R scaling coefficient, $\theta_{A t t n}$, is constrained to be negative to represent $\mathrm{Q}$ effects. The minus in front of $\theta_{\text {Attn }} R_{\text {Rup }}$ term indicates the linear R scaling from the ergodic GMM is removed so that a similar constraint on the attenuation from ergodic model $\left(\theta_{A t t n, i}<0\right.$ for each cell) can be applied to the non-ergodic model.

The total residuals, $\varepsilon_{e s}$, are modeled in two steps to estimate these non-ergodic terms: (1) the source and site terms using the VCM via a Gaussian process regression (Landwehr et al., 2016), and (2) the path term of anelastic attenuation per cell from the cell-specific approach using the Bayesian hierarchical model (Kuehn et al., 2019). These two steps are described below.

\subsection{Source and site terms for the VCM}

Using eq.4 and eq.5, the total residuals from the ergodic model are modeled using the functional form in eq.7:

$$
\varepsilon_{e s}=C_{0}+\beta_{-1}\left(\mathbf{t}_{\mathbf{e}}\right)+\beta_{0}\left(\mathbf{t}_{\mathbf{s}}\right)+f_{V s 30}\left(V s 30 ; \mathbf{t}_{\mathbf{s}}\right)+\delta B_{e}+\delta S_{S 2 S}^{\prime}+\delta W S_{e s} .
$$

in which $C_{0}$ is the intercept that accounts for the change in the implicit weighting for each recording due to the inclusion of spatial correlations; $\delta B_{e}$ is the remaining aleatory variability of the event term; and $\delta W S_{e s}$ is the remaining aleatory variability of within-site term. The $\delta S_{S 2 S}^{\prime}$ has the same role as $\delta S_{S_{2} S}$ for the single-station standard deviation approach, but it is computed relative to the site scaling in the VCM model.

The median ground motion using the VCM model is given by

$$
\mu_{V C M}\left(\mathbf{M}, \mathbf{R}, \mathbf{S}, \mathbf{t}_{e}, \mathbf{t}_{\mathbf{s}}, \ldots\right)=\mu_{\text {erg }}(\mathbf{M}, \mathbf{R}, \mathbf{S}, \ldots)+C_{0}+\beta_{-1}\left(\mathbf{t}_{\mathbf{e}}\right)+\beta_{0}\left(\mathbf{t}_{\mathbf{s}}\right)+f_{V S 30}\left(V_{S 30} ; \mathbf{t}_{\mathbf{s}}\right)
$$

and the total residuals from the VCM are given by:

$$
\eta_{e s}=\ln \left(E A S_{e s}\right)-\mu_{V C M}\left(\mathbf{M}, \mathbf{R}, \mathbf{S}, \mathbf{t}_{\mathbf{e}}, \mathbf{t}_{\mathbf{s}}, \ldots\right)
$$

The regression approach for the VCM is the Gaussian-process (GP) regression with a hierarchical Bayesian framework. The GP is a distribution over a function $f(x)$, and its distribution is defined by a mean function and a covariance function:

$$
\boldsymbol{f}(\mathbf{x}) \sim G P\left(0, \kappa\left(\mathbf{x}, \mathbf{x}^{\prime}\right)\right),
$$

in which $\mathbf{x}$ is for the data (earthquakes and stations) and $\mathbf{x}$ ' is the for the prediction. Because we are fitting the model to the residuals from the ergodic GMM, the mean function is set to 0 and the $\mathrm{x}=\left(\mathbf{t}_{\mathbf{e}}, \mathbf{t}_{\mathbf{s}}\right)$ and $\mathrm{x}^{\prime}=\left(\mathbf{t e}_{\mathbf{e}}, \mathbf{t}_{\mathbf{s}}{ }^{\prime}\right)$ into covariance function. The covariance function model is the joint distribution of all random variables to build the distribution over a function with a continuous domain, such as location of event or site. We set the covariance function (also known as the kernel function) of VCM to be consistent with Landwehr et al. (2016):

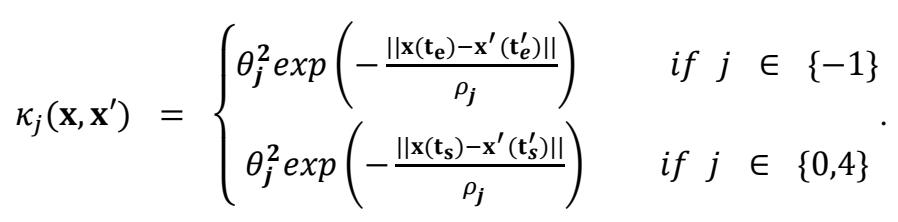

177 in which $\theta^{2}$ is the variance (amplitude) and $\rho$ is the correlation length (length scale); they are the hyperparameter 178 in the kernel function, and $j$ is the index of the coefficient. The prior distributions for hyperparameters are modeled 
as exponential distribution and inverse gamma distribution:

$$
\boldsymbol{\theta} \sim \exp (20)
$$

$$
\boldsymbol{\rho} \sim \operatorname{Inv} \_ \text {Gamma }(2,0.5)
$$

We estimate the hyperparameters of the Gaussian process via the marginal likelihood based on the Markov chain Monte Carlo (MCMC) sampling in the program Rstan (Stan Development Team, 2020). We adopted 800 iterations per chain (4 chains in total) and chose the default of the burnin (iteration/2). The mean value of the posterior distribution of the hyperparameter of eq.11 is listed in Table 1, from $1.0 \mathrm{~Hz}$ to $23.5 \mathrm{~Hz}$.

The mean prediction and standard deviation of the epistemic uncertainty $(\Psi)$ associated with ground-motion median predictions for different locations is given by equation (10) and equation (11) in Landwehr et al (2016):

$$
\begin{aligned}
\mu & =\mathbf{k}^{\mathbf{T}}\left(\mathbf{K}+\sigma_{0}^{2} \mathbf{I}\right)^{-1} \mathbf{y}, \\
\Psi^{2} & =\mathbf{k}_{*}-\mathbf{k}^{\mathbf{T}}\left(\mathbf{K}+\sigma_{0}^{2} \mathbf{I}\right)^{-1} \mathbf{k},
\end{aligned}
$$

$\mathbf{k}=\left[k_{1}, k_{2}, \cdots, k_{n-1}, k_{n}\right] \quad$ and $\quad k_{i}=\sum_{m=1}^{d} x_{i m} x_{* m} \kappa_{m}\left(t_{i}, t_{*}\right)$,

in which $\mathbf{y}$ is the observation data, $\mu$ is the mean prediction, $\Psi$ is the standard deviation of epistemic uncertainty for site location. $x_{*}$ denotes the new predictor variable for a new location $t_{*} x_{i}$ and $x_{l}$ are the $i$ th and $l$ th predictor variable for the existing location $t_{i}$ and $t_{l}$, respectively. $\kappa_{j}$ is from the eq.11, $\mathbf{I}$ is the identity matrix, $\sigma_{0}$ are the standard deviation of aleatory variability of the ground motion, $d$ is the number of non-ergodic coefficients in the model, and $\mathrm{n}$ is the number of data points.

For the median model, we only need the non-ergodic terms, so the $\sigma_{0}$ of the ground motion is not included in calculating the epistemic uncertainty in eq. 14 and eq. 15. The non-ergodic coefficients at the locations (e.g., $t_{i}$ and $t_{l}$,) are not known, so we assumed the non-ergodic coefficients follow a multivariate normal posterior distribution:

$$
\beta_{j, n} \sim \mathcal{N}\left(\mu_{\beta_{i, n}}, \Psi_{\beta_{i, n}}\right), j \in\{-1,0,4\}
$$

in which $\beta_{j, n}$ is the non-ergodic coefficient at the $n$th existing location, $\mu_{\beta_{i, n}}$ is the posterior mean, and $\Psi_{\beta_{i, n}}$ is the posterior variances. The epistemic uncertainty of $\mu_{\beta_{i, n}}$ can be accounted in predicting $\mu_{\beta_{j}^{*}}$ by using the marginal distribution of $\mu_{\beta_{j}^{*}}$. Based on these assumptions, the mean prediction and the epistemic uncertainty associated with non-ergodic coefficient predictions for new locations is given by (Lavrentiadis et al. 2021)

$$
\begin{gathered}
\mu_{\beta_{j}^{*}}=\mathbf{k}^{\mathbf{T}} \mathbf{K}^{-1} \boldsymbol{\mu}_{\boldsymbol{\beta}_{j}}, \\
\Psi_{\beta_{j}^{*}}^{2}=\mathbf{k}_{*}-\mathbf{k}^{\mathbf{T}} \mathbf{K}^{-1} \mathbf{k}+\left(\mathbf{k}^{\mathbf{T}} \mathbf{K}^{-1}\right) \Psi_{\beta_{i}}\left(\mathbf{k}^{\mathbf{T}} \mathbf{K}^{-1}\right)^{T},
\end{gathered}
$$

We adopted the eq.20 and eq.21 to calculate the mean prediction and epistemic uncertainties of the $\beta_{-1}, \beta_{0}$, and $\beta_{4}$ for each source location and site location are estimated. For the non-ergodic PSHA calculations, these epistemic uncertainties of the adjustments for each source cell and site location are considered in the logic tree with a map of the non-ergodic terms on each branch of the logic tree for the GMM.

To show the adjustment map of source constant $\left(\beta_{-1}\right)$, site constant $\left(\beta_{0}\right)$, and $\ln \left(\mathrm{VS}_{30}\right)$ coefficient $\left(\beta_{4}\right)$, we divide France into cells of size $0.2 \times 0.2$ degrees. The correlation lengths shown in Table 1 are larger than 0.2 so, this grid size is adequate. The mean values of the three non-ergodic coefficients are computed for each cell using 
215

either the source location or site location. Maps of the spatially varying mean coefficients are shown in Fig. 4 for $1 \mathrm{~Hz}$ and $5 \mathrm{~Hz}$. These adjustment terms are zero in regions without data (or with sparse data) and potentially show the positive values or negative values for cells close to observed events or seismic stations.

\subsection{Path-specific attenuation term}

The same 0.2 x 0.2 degrees grid size is used for the cells for the non-ergodic path effects. Fig. 5 shows the number of rays that pass through each cell at $5 \mathrm{~Hz}$. For eastern and southern France, there are data to provide good constraints on the path effect per cell. We apply the cell-specific anelastic attenuation terms to replace an ergodic term in the GMM and use the same regression model (Bayesian hierarchical model) and settings of the prior distributions following Kuehn et al. (2019) in program Rstan. The setting of the iteration and burnin parameters are same as used earliern. The cell-specific anelastic attenuation terms are estimated using this following form:

$$
\ln \left(E A S_{e s}\right)=\mu_{V C M}\left(\mathbf{M}, \mathbf{R}, \mathbf{S}, \mathbf{t}_{\mathbf{e}}, \mathbf{t}_{\mathbf{s}}, \ldots\right)-c_{7} R_{\text {rup }}+f_{A t t n}\left(\Delta R_{R u p, i} ; \mathbf{c e l l}_{i}\right)+\partial B_{e}+\partial S 2 S_{s}+\partial W_{s, e s} .
$$
in which $f_{A t t n}\left(\Delta R_{R u p, i} ; \operatorname{cell}_{i}\right)=\sum_{i}^{N c} \theta_{A t t n, i} \Delta R_{R u p, i}$, and $\partial W_{s, e s}$ is the remaining variability of the within-site term. The $c_{7} R_{\text {rup }}$ term is the linear $\mathrm{R}$ scaling of the ergodic GMM (eq. 2). To avoid nonphysical attenuation coefficients, the $\theta_{A t t n, i}$ terms are constrained to be negative.

Fig. 5 also shows the mean of posterior distribution of the $\theta_{A t t n, i}$ per cell at $5.0 \mathrm{~Hz}$. There are larger mean anelastic attenuation coefficients (lower Q) in the Alps region and smaller mean values (higher Q) in western France. If a cell does not include any ray paths, the mean cell-specific anelastic attenuation coefficient will become equal to the ergodic anelastic attenuation value ( $c_{7}$ in eq.2). Sung and Abrahamson (2020) show a comparison of the Q models from Campillo and Plantet (1991) and Mayor et al. (2018). These Q studies show lower Q values in the south-eastern regions and higher Q values in the western areas consistent with the non-ergodic terms. The standard deviation of the epistemic uncertainty of the $\theta_{A t t n, i}$ is captured from the posterior distribution. As with the epistemic uncertainties of VCM, these epistemic uncertainties for each source cell are included on the logic tree in the nonergodic PSHA calculations.

\subsection{Residuals \& standard deviation}

The residuals of the ergodic and fully non-ergodic (combine VCM and path effects) GMMs for 5.0 Hz are shown in Fig. 6. The results show a significant reduction of the variability of the between-event and between-site residuals for the non-ergodic model as compared to the ergodic model. The main reason for an inflated estimate of aleatory variability of the ergodic GMM is that systematic source, site, and path effects are assumed to be random and ply to all sites. In contrast, the non-ergodic model incorporates the repeatable systematic source, path, and site effects into the GMM.

Fig. 7 shows the aleatory standard-deviations terms for the ergodic, partially non-ergodic, and fully nonergodic GMMs for each frequency. There is a significant reduction of the aleatory variability for the non-ergodic model. For example, at $5 \mathrm{~Hz}$, the ergodic aleatory standard deviation is 0.94 , the partially non-ergodic aleatory standard deviation (the single station standard deviation) is 0.76 , and the non-ergodic aleatory standard deviation is 0.59. This corresponds to a $60 \%$ reduction in variance from the ergodic to the non-ergodic GMM and is consistent with the results from previous studies for active regions discussed in the introduction. 


\section{Median EAS prediction and uncertainty for non-ergodic model}

252 Because the adjustment terms of a non-ergodic GMM vary by the geographical location, the median predictions at

253 a given site also change depending on event locations. Fig. 8 shows an example of the spatial variation of median

254 EAS predictions by the French non-ergodic GMMs for a set of predictor variables $\mathrm{M}=5.0, \mathrm{~V}_{\mathrm{S} 30}=2100 \mathrm{~m} / \mathrm{s}, \mathrm{Z}_{\text {TOR }}$

$255=10 \mathrm{~km}$ at $5.0 \mathrm{~Hz}$ for Site 1 in southeastern France $\left(43.6748^{\circ} \mathrm{N}, 5.7664^{\circ} \mathrm{E}\right)$. Comparing these two models, the ergodic

256 GMM shows the same attenuation in all directions, but for the non-ergodic GMM, the attenuation can depend on 257 the direction based on the non-ergodic terms.

258 Fig. 9 compares the distance scaling of the EAS in different directions for the ergodic and non-ergodic models 259 at $5.0 \mathrm{~Hz}$ for two sites: Site 1 and Site $2\left(47.2294{ }^{\circ} \mathrm{N}, 0.1673^{\circ} \mathrm{W}\right)$. The largest differences are seen for distances of $260 \quad 100-300 \mathrm{~km}$ due to the path effects. The standard deviation of the epistemic uncertainty of the median ground motion 261 for the non-ergodic model for two sites shown in Fig. 10. This epistemic uncertainty is from the combination of the 262 standard deviation of posterior distribution for all the non-ergodic terms (source, site, and path). The results show 263 the lower uncertainty is constrained to locations where data are available, whereas the uncertainty is larger for the 264 region with sparse or no data. All epistemic uncertainties for the Site 1 are lower than the resulting of Site 2, which reflects the smaller uncertainty of the site term for Site 2 than for Site 1.

We use the same parameters $\left(\mathrm{V}_{\mathrm{S} 30}=2100 \mathrm{~m} / \mathrm{s}, \mathrm{Z}_{\mathrm{TOR}}=10 \mathrm{~km}\right)$ to calculate the median EAS spectra at $1.0 \mathrm{~Hz}$ to $23.5 \mathrm{~Hz}$ for two target sources which have the same source-site distance of $247 \mathrm{~km}$. The first target source (Source $1,43.7^{\circ} \mathrm{N}, 2.7^{\circ} \mathrm{E}$ ) is located west of the site, and the second source (Source $2,45.9^{\circ} \mathrm{N}, 5.7^{\circ} \mathrm{E}$ ) is located north of the site. Fig. 11 compares the median EAS spectra from the non-ergodic and ergodic models from M3 to M7. For Source 1, the ergodic and non-ergodic models have similar Fourier spectra, but for Source 2, there is significant difference at frequencies greater than $2 \mathrm{~Hz}$ between non-ergodic and ergodic models. Source 2 has observed data nearby so shows a large adjustment for the non-ergodic model. Fig. 11 also shows the epistemic uncertainties of the non-ergodic model at all frequencies for Source 1 and Source 2, respectively. Source 2 has a smaller epistemic uncertainty than Source 1 due to the available earthquakes near Source 2.

\section{Examples for non-ergodic hazard calculations}

For PSHA implementation of the non-ergodic approach, the site/source specific adjustment along with the standard deviation of epistemic uncertainty in the adjustment needs to be included. The current approach is to precompute the net adjustment term (sum of the non-ergodic terms) for each source location for a single site location. We randomly sample 100 different adjustments maps from the distribution of the epistemic uncertainty of the nonergodic terms. Fig.12 shows the two samples of 100 maps for sampled adjustments, the range of latitude and longitude is from $40^{\circ} \mathrm{N}$ to $52^{\circ} \mathrm{N}$ and $6^{\circ} \mathrm{W}$ to $12^{\circ} \mathrm{E}$, respectively. In PSHA calculation, we add these adjustments to the median ground motion from the ergodic model. In this approach, there is a logic tree with 100 branches of the non-ergodic terms for the GMM that are equally weighted (Fig. 13).

For the site terms, a single non-ergodic term is estimated for each realization. The source and path non-ergodic terms are sampled to capture the variance and the correlations of the terms. The net adjustment is the sum of the 
287 program. The main change is that the adjustment terms depend on the latitude and longitude of the source.

288 The following is the formula for the ergodic probability of exceeding any PGA level using knowledge of the median ground motion $\left(\mu_{\text {erg }}\right)$ and ergodic aleatory standard deviation $\left(\sigma_{\text {erg }}\right)$ in the units:

$$
P(Y>Z \mid M, R)=1-\Phi\left(\frac{\ln (z)-\mu_{\operatorname{erg}(M, R, T)}}{\sigma_{\operatorname{erg}}(M, R, T)}\right)
$$

Where the $\mathrm{Y}$ is the ground-motion parameter of interest, and $P(Y>Z \mid M, R)$ is the conditional probability that $\mathrm{Y}$ is larger than $\mathrm{z}$ for a given magnitude, distance, and other relevant parameters. $\Phi()$ is the cumulative distribution function of a standard normal distribution. But for non-ergodic GMMs, the latitude and longitude of each source needs to be passed to the GMM subroutine and the appropriate adjustment factor interpolated from the precalculated values.

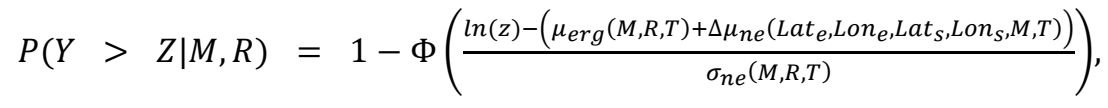

The HAZ45 code runs the hazard for a single site, so the $\Delta \mu_{n e}$ is a table of adjustments for different source locations and magnitudes for the selected site, and the $\sigma_{n e}$ is the non-ergodic aleatory standard deviation. Multiple realizations are included to capture the epistemic uncertainty in the non-ergodic terms. Fig.14 shows the mean and standard deviation of adjustment over the 100 realization for Site 1 and Site 2 per source grid. For sites without local data (e.g., Site 2), the mean values in the maps are close to zero. For sites will location data to constrain the non-ergodic terms (e.g., Site 1), the mean can be close to zero or different from zero depending on the data. The epistemic uncertainties range from 0.3 for regions with local data to 0.7 for regions without local data. It should be similar to the previous epistemic uncertainty map (Fig.10) because we adopted these epistemic uncertainties to generate the samples (adjustments) for each cell.

Fig. 15 compares the hazard using the ergodic EAS GMM with the hazard from the 100 samples of the nonergodic adjustment terms for two sites, the seismic source model is the EDF zoning (Drouet et al., 2020): Site1 (close to the local data) and Site2. For Site 1, there is a large reduction in the mean non-ergodic hazards for $5 \mathrm{~Hz}$. At an annual frequency of exceedance of $1 \times 10^{-4}$, there is a factor of 1.6 reduction in the ground France motion, and the 95th fractile from the non-ergodic hazard is close to the mean ergodic hazard. The slope of the median hazard is steeper than the slope of the mean hazard. For Site 2, the 5-Hz mean hazard are similar the mean ergodic hazard results. The adjustments for Site 2 are small due to the spare available data in this region, and there is increased epistemic uncertainty leading to a wider range of the fractiles than Site 1.

For the non-ergodic GMM, if only the aleatory variability is reduced, then the non-ergodic hazard curves would be much steeper than the ergodic hazard curves; however, the adjustments vary spatially, which acts like additional variability in the total hazard (summed over all source locations). So, the non-ergodic hazard curves are not as steep as would be the case if the adjustment was the same for all source locations, as is the case with the partially nonergodic single-station sigma approach. The mean hazard also samples the epistemic uncertainty from the 100 realizations which will also flatten the slope of the mean hazard curve for large epistemic uncertainty. The effect of the epistemic uncertainty on the slope of the hazard curve can be seen by comparing the slope from the mean hazard and the slope from the median hazard.

\section{Conclusions}


323 Traditionally, GMMs used in PSHA have been based on the ergodic assumption (Anderson and Brune 1999). The 324 move to non-ergodic GMMs will lead to GMMs that have a better physical basis and provide more accurate 325 estimates of the hazard in regions with local data. In regions with little local data, non-ergodic GMMs can still be 326 used. In this case, the mean hazard will approximate the ergodic mean hazard, but the uncertainty range will be 327 broader and will provide a better estimate of the uncertainty and the value of collecting local ground-motion data.

328 The non-ergodic GMM was developed for EAS rather than PSA to avoid the scaling issue being affected by 329 differences in the response spectral shape. The non-ergodic GMM for EAS develop in this study can be extended to 330 response spectral values using random vibration theory (see Phung and Abrahamson 2021 for an example). Before 331 doing so, the extrapolation to low frequencies should be revised. Because the available data ground-motion from 332 France were not reliable at low frequencies, the current model assumed that the low-frequency scaling from the 333 BA19 model is applicable to France at frequencies less than $1 \mathrm{~Hz}$. This can be improved. It may be possible to use 334 the hyperparameters for low frequencies from the California models and then estimate the non-ergodic terms using 335 the French data.

336 Using a non-ergodic GMM, there is a large reduction in the aleatory standard deviation, but there is also a shift 337 in the median from each source location that can be either positive (large median) or negative (smaller median). At 338 the $1 \times 10^{-4}$ annual frequency of exceedance, there tends to be a reduction in the hazard using the non-ergodic 339 GMM, but at some sites, there will be an increase in the hazard if there is an increase in the medians for the 340 controlling sources that offsets the reduction in the aleatory standard deviation at the $1 \times 10^{-4}$ annual frequency 341 of exceedance.

Acknowledgments We are grateful to Prof. John Douglas and Prof. Christophe Martin for their comments. We 344 deeply appreciate the ground-motion database flatfile provided by the SIGMA-2 Project (https://www.sigma-2.net/).

345 Partial funding for this study was provided by EDF as part of the SIGMA-2 project.

\section{Declarations}

348 Funding: Partial funding for this study was provided by EDF as part of the SIGMA-2 project.

349 Conflicts of interest/Competing interests: The authors declare no competing interests.

350 Ethics approval: Non applicable

351 Consent to participate: Non applicable

352 Consent for publication: Non applicable

353 Availability of data and material:

354 https://github.com/KarenCHSung (Not finished yet)

\section{Code availability:}

356 https://github.com/KarenCHSung (Not finished yet)

\section{References}


Abrahamson NA, Youngs RR (1992) A stable algorithm for regression analyses using the random effects model. Bull Seism Soc Am. 82:505-510.

Abrahamson NA, Silva WJ, Kamai R (2014) Summary of the ASK14 ground motion relation for active crustal regions. Earthq Spectra. 30 (3):1025-1055.

Abrahamson NA, Kuehn NM, Walling M, Landwehr N (2019) Probabilistic seismic hazard analysis in california using non-ergodic ground-motion models. Bull Seism Soc Am 109 (4): 1235-1249.

Al Atik, L., Abrahamson N A., Cotton F, Scherbaum F, Bommer JJ, Kuehn N (2010). The variability of groundmotion prediction models and its components, Seismol. Res. Lett. 81, no. 5, 794-801.

Allen TI, Wald DJ (2009) On the use of high-resolution topographic data as a proxy for seismic site conditions (Vs30). Bull Seismol Soc Am, 99 (2A): 935-943.

Anderson J, Brune JN (1999) Probabilistic seismic hazard assessment without the ergodic assumption. Seism Res Lett 70: 19-28.

Anderson JG, Uchiyama Y (2011). A methodology to improve ground-motion prediction equations by including path corrections, Bull Seismol Soc Am 101: 1822-1846.

Atkinson GM (2006). Single-station sigma, Bull. Seism. Soc. Am., 96, 446-455.

Bayless J, Abrahamson NA (2019) Summary of the BA18 Ground-Motion Model for Fourier Amplitude Spectra for Crustal Earthquakes in California. Bull Seismol Soc Am. 109(5): 2088-2105.

BC Hydro (2012). Dam safety probabilistic seismic hazard analysis (PSHA) model, Technical Report, Report No. E658, Vancouver, British Columbia.

Bommer JJ, Abrahamson NA (2006). Why do modern probabilistic seismic-hazard analyses often lead to increased hazard estimates. Bull. Seismol. Soc. Am. 96, 1967-1977.

Bommer JJ, Coppersmith KJ, Coppersmith RT, Hanson KL, Mangongolo A, Neveling J, Rathje EM, RodriguezMarek A, Scherbaum F, Shelembe R, et al. (2015) A SSHAC Level 3 probabilistic seismic hazard analysis for a new-build nuclear site in South Africa. Earthq Spectra. 31 (2), 661-698.

Boore DM, Stewart JP, Seyhan E, Atkinson GM (2014). NGAWest2 equations for predicting PGA, PGV, and 5\% damped PSA for shallow crustal earthquakes, Earthq. Spectra 30, no. 3, 1057-1085.

Bora SS, Cotton F, Scherbaum F (2019) NGA-West2 empirical Fourier and duration models to generate adjustable response spectra. Earthq Spectra. 35 (1): 61-93.

Bremaud V, Traversa P (2019) Determination of GMPEs based on different intensity measures, SIGMA2 project, SIGMA2-2019-D3-028, France.

Brune JN (1970). Tectonic stress and spectra of seismic shear waves from earthquakes. J Geophys Res. 75: 49975009.

Campbell KW, Bozorgnia Y (2014) NGA-West2 ground motion model for the average horizontal components of PGA, PGV, and 5\% damped linear acceleration response spectra. Earthq Spectra. 30 (3): 1087-1115.

Campillo M, Plantet J (1991) Frequency dependence and spatial distribution of seismic attenuation inFrance: experimental results and possible interpretations. Phys Earth Planet Inter. 67(1):48-64. 
Cara M, Cansi Y, Schlupp A, Arroucau P, Béthoux N, Beucler E, Bruno S, Calvet M, Chevrot S, Deboissy A, et al. (2015). SI-Hex: A new catalogue of instrumental seismicity for metropolitan France. Bull Soc Géol France $186(1): 3-19$.

Carpenter B, Gelman A, Hoffman M, Lee D, Goodrich B, Betancourt M, Brubaker MA, Li P, Riddell A (2016). Stan: A probabilistic programming language. J. Stat. Software. 76: 1-32.

Chiou B, Darragh RB, Gregor N., Silva WJ (2008) NGA project strong-motion database. Earthq Spectra. 24 (1): 23-44.

Chiou B, Youngs RR, Abrahamson N, Addo K (2010) Ground-motion attenuation model for small-tomoderate shallow crustal earthquakes in California and its implications on regionalization of ground-motion prediction models. Earthq Spectra. 26: 907-926.

Chiou, B., Youngs RR (2014). Update of the Chiou and Youngs NGA model for the average horizontal component of peak ground motion and response spectra, Earthquake Spectra 30(3) 1117-1153.

Coppersmith K, Bommer JJ, Hanson K, Coppersmith R, Unruh J, Wolf L, Youngs R, Al Atik L, Rodriguez-Marek A, Toro G (2014) Hanford sitewide probabilistic seismic hazard analysis. Technical Report Prepared for the U.S. Department of Energy Under Contract DE-AC06076RL01830, and Energy Northwest, Pacifc Northwest National Lab Report PNNL-23361, November.

Dawood HM, Rodriguez-Marek A (2013) A method for including path effects in ground-motion prediction equations: An example using the Mw 9.0 Tohoku earthquake aftershocks. Bull Seismol Soc Am. 103 (2B): 1360-1372.

Drouet, S., G. Ameri, K. L. Dortz, R. Secanell, and G. Senfaute (2020). A probabilistic seismic hazard map for the metropolitan France. Bulletin of Earthquake Engineering. 18: 1865-1898.

Geopentech (2015) Southwestern United States ground motion characterization SSHAC level 3 - Technical Report Rev. 2, March 2015. Technical report.

Goulet CA, Kottke A, Boore DM, Bozorgnia Y, Hollenback J, Kishida T, Der Kiureghian A, Ktenidou OJ, Kuehn NM, Rathje EM, et al. (2018) Effective amplitude spectrum (EAS) as a metric for ground motion modeling using Fourier amplitudes. 2018 Seismology of the Americas Meeting, Miami, Florida: 14-17.

Grünthal G, Stromeyer D, Wahlström R (2009) Harmonization check of Mw within the central, northern, and northwestern European earthquake catalogue (CENEC), J. Seismol. 13(4): 613-632.

Konno K, Ohmachi T (1998) Ground-motion characteristics estimated from spectral ratio between horizontal and vertical components of microtremor. Bull Seismol Soc Am. 88: 228-241.

Kotha SR, Bindi D, Cotton F (2016) Partially non-ergodic region specific GMPE for Europe and Middle-East. Bull Earthq Eng 14 (4): 1245-1263.

Kottke A, Rathje E, Boore DM, Thompson E, Hollenback J, Kuehn N, Goulet CA, Abrahamson NA, Bozorgnia Y, Der Kiureghian A (2018) Selection of random vibration procedures for the NGA east project. PEER Rept. No. 2018/05, Pacific Earthquake Engineering Research Center, University of California, Berkeley, California.

Kuehn NM, Abrahamson NA, Walling MA (2019) Incorporating non-ergodic path effects into the NGA-West2 ground-motion prediction equations. Bull Seismol Soc Am 109 (2): 575-585. 
Landwehr N, Kuehn NM, Scheffer T, Abrahamson NA (2016) A non-ergodic ground-motion model for California with spatially varying coefficients. Bull Seismol Soc Am 106 (6): 2574-2583.

Lanzano G, D’Amico M, Felicetta C, Luzi L, Puglia R (2017) Update of the single-station sigma analysis for the Italian strong-motion stations. Bull Earthq Eng. 6: 2411-2428.

Lavrentiadis G, Abrahamson NA, Kuehn NM (2021) A Non-ergodic Effective Amplitude Ground-Motion Model for California. Bull Earthq Eng (submitted)

Lin, PS, Chiou B, Abrahamson NA, Walling M, Lee CT, Cheng CT (2011) Repeatable source, site, and path effects on the standard deviation for empirical ground-motion prediction models. Bull Seismol Soc Am. 101: 22812295.

Mayor J, Traversa P, Calvet M (2018) Tomography of crustal seismic attenuation in Metropolitan France: implications for seismicity analysis. Bull Earthq Eng 16: 2195-2210.

Pinheiro J, Bates D, DebRoy S, Sarkar D, the R Core Team (2020) nlme: Linear and nonlinear mixed effects models. R package version 3:1-145.

Phung VB, Abrahamson NA (2021) Conditional Ground Motion Model for Pseudo Spectral Acceleration (PSA) Using Fourier Amplitude Spectra (FAS), Bull Earthq Eng (submitted)

Power M, Chiou B, Abrahamson NA, Bozorgnia Y, Shantz T, Roblee C (2008) An overview of the NGA project. Earthq Spectra 24(1): 3-21.

Renault P, Heuberger S, Abrahamson NA (2010) PEGASOS refinement project: An improved PSHA for Swiss nuclear power plants. Proc. of 14ECEE_European Conf. of Earthquake Engineering, Paper ID 991.

Réseau Sismologique et géodésique Français (RESIF) (1995) RESIF-RLBP French Broad-band Network, RESIFRAP strong motion network and other seismic stations in metropolitan France. RESIF - Réseau Sismologique et géodésique Français, doi: 10.15778/ RESIF.FR.

Rodriguez-Marek A, Cotton F, Abrahamson NA, Akkar S, Al Atik L, Edwards B, Montalva G, Dawood H (2013) A model for single-station standard deviation using data from various tectonic regions. Bull Seismol Soc Am 103: 3149-3163.

Stan Development Team (2020). RStan: the R interface to Stan. R package version 2.21.2. http://mc-stan.org/.

Sung CH, Abrahamson, NA (2020). Implementation of Non-Ergodic Ground Motion Prediction Equations in Probabilistic Seismic Hazard Analysis for France. Deliverable SIGMA2 project. Ref. SIGMA2-2020-D5-059.

Sung CH, Lee CT (2019). Improvement of the quantification of epistemic uncertainty using single-station groundmotion prediction equations. Bull Seismol Soc Am 109 (4): 1358-1377.

Traversa P, Maufroy E, Hollender F, Perron V, Bremaud V, Shible H, Drouet S, Guéguen P, Langlais M, Wolyniec D, Péquegnat C, Douste-Bacque I (2020). RESIF RAP and RLBP dataset of earthquake ground motion in mainland France. Seismol Res Lett 91 (4): 2409-2424.

Tromans IJ, Aldama-Bustos G, Douglas J, Lessi-Cheimariou A, Hunt S, Davi M, Musson RMW, Garrard G, Strasser FO, Robertson C (2019) Probabilistic seismic hazard assessment for Francea new-build nuclear power plant site in the UK. Bull Earthquake Eng 17(1): 1-36.

Wald DJ, Allen TI (2007) Topographic slope as a proxy for seismic site conditions and amplification. Bull Seismol Soc Am 97(5): 1379-1395. 


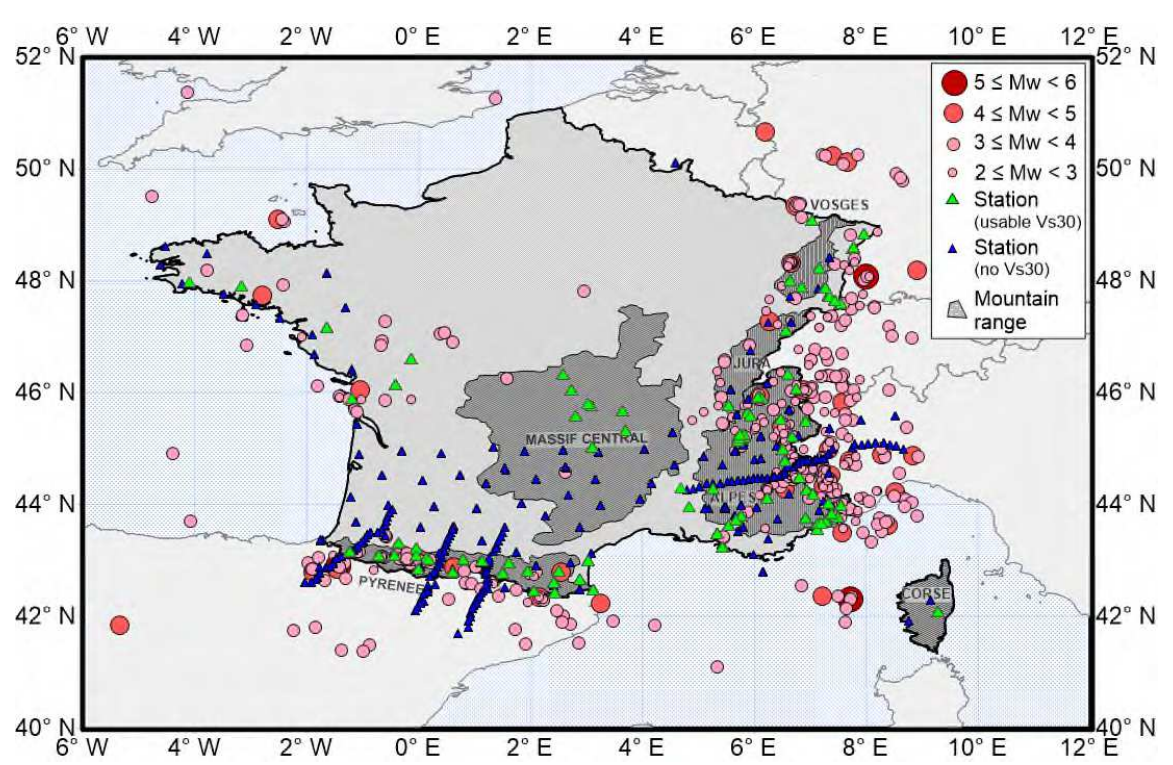

472 Fig. 1 Map showing locations of the strong-motion stations and crustal earthquakes of France used in this study.

473 The circles indicate the earthquake epicenters and the triangles indicate the locations of the stations.

474

475
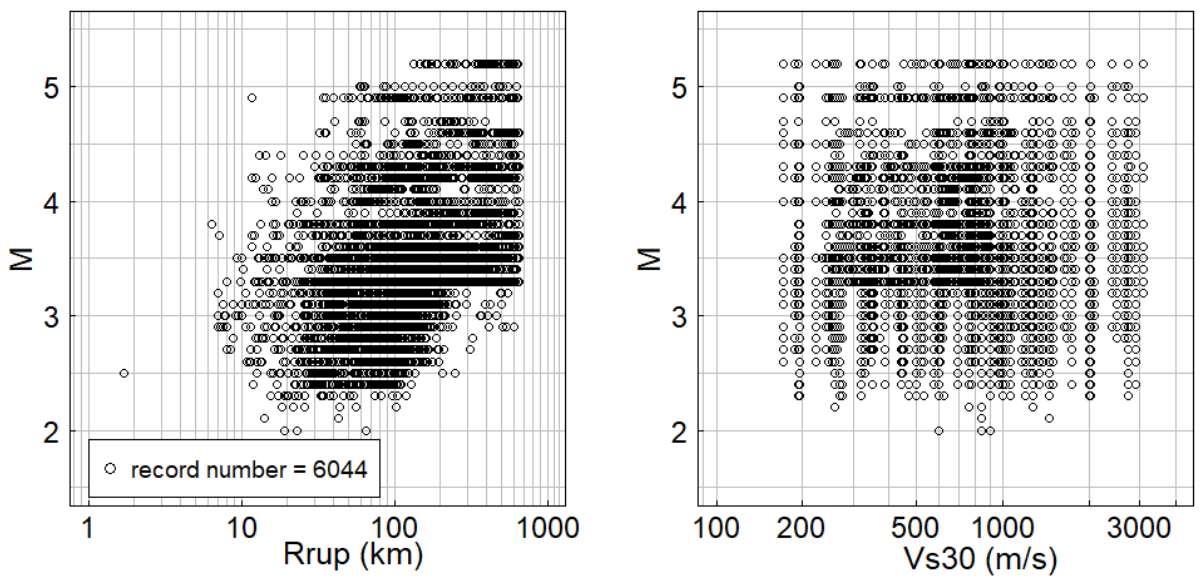

Fig. 2 Magnitude-distance and -Vs30 distribution of subset database. 

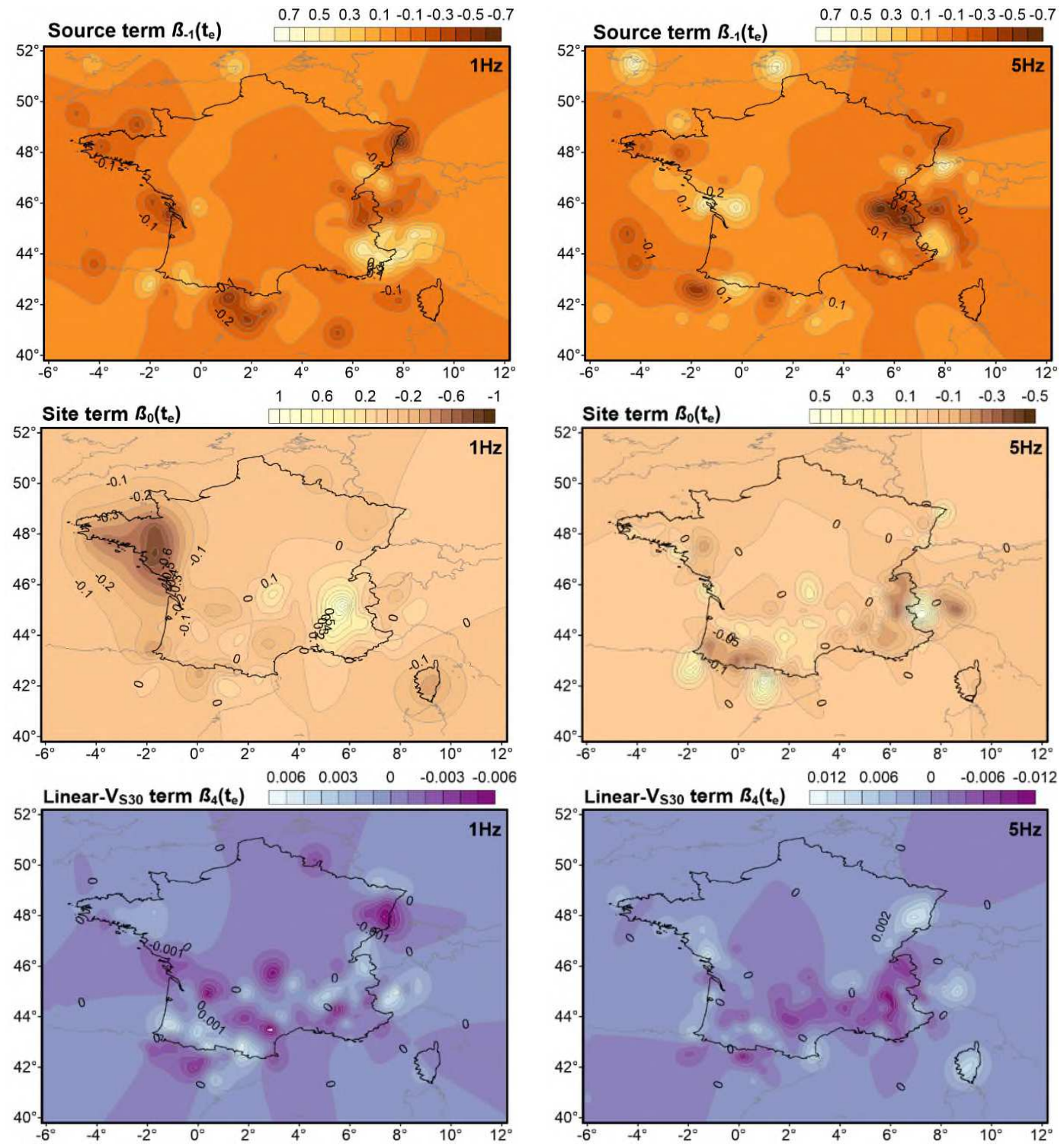

Fig. 3 Spatially varying adjustment of constant event term (Top), constant site term (Middle), and linear- $\mathrm{V}_{\mathrm{S} 30}$ scaling 481 term (Bottom) at $1.0 \mathrm{~Hz}$ and $5.0 \mathrm{~Hz}$.

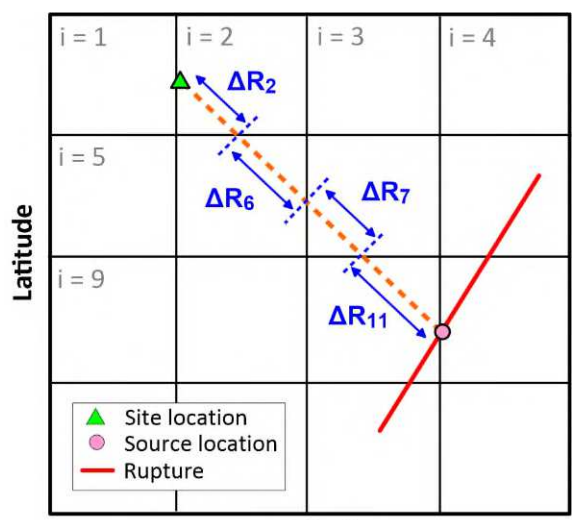

Longitude

483 Fig. 4 Schematic showing how the length of the ray in the ith cell are calculated for the regression of the cell-

484 specific attenuation coefficients (Kuehn et al., 2019). 

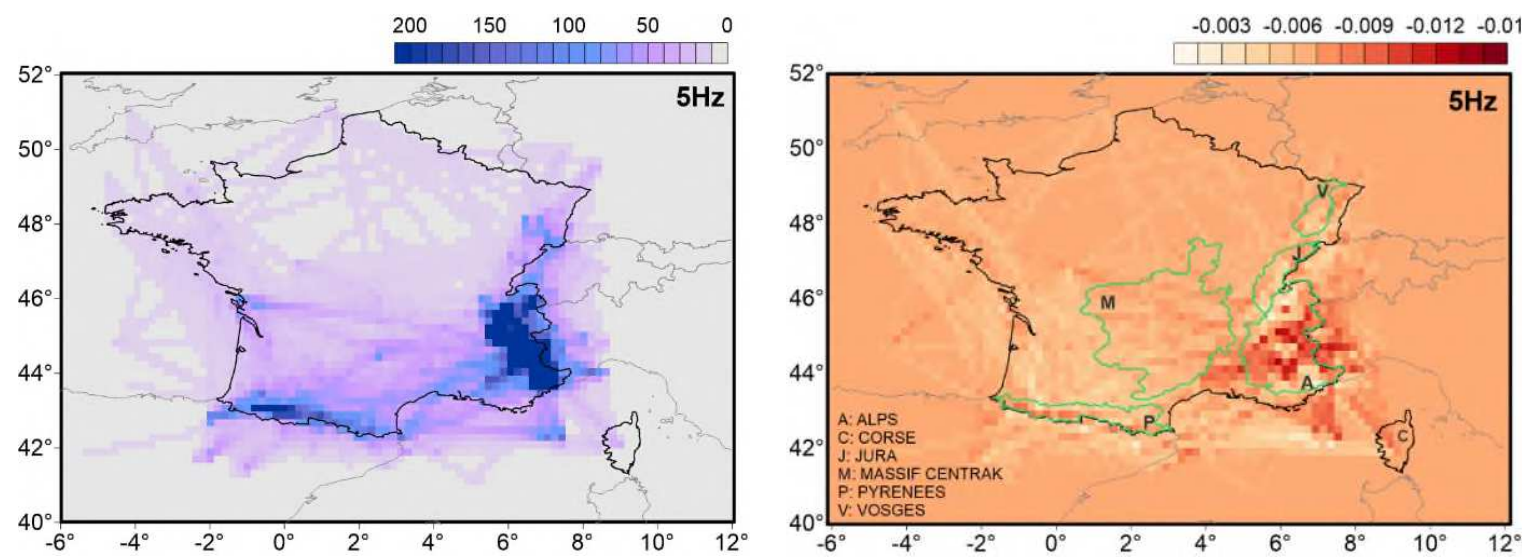

485

Fig. 5 Left Number of paths per cell, the cell size is 0.2 times 0.2 degrees. Right Mean values of the posterior distribution of the $\theta_{\text {Attn }}$ per cell for $5.0 \mathrm{~Hz}$. Green lines are mountain regions.

487
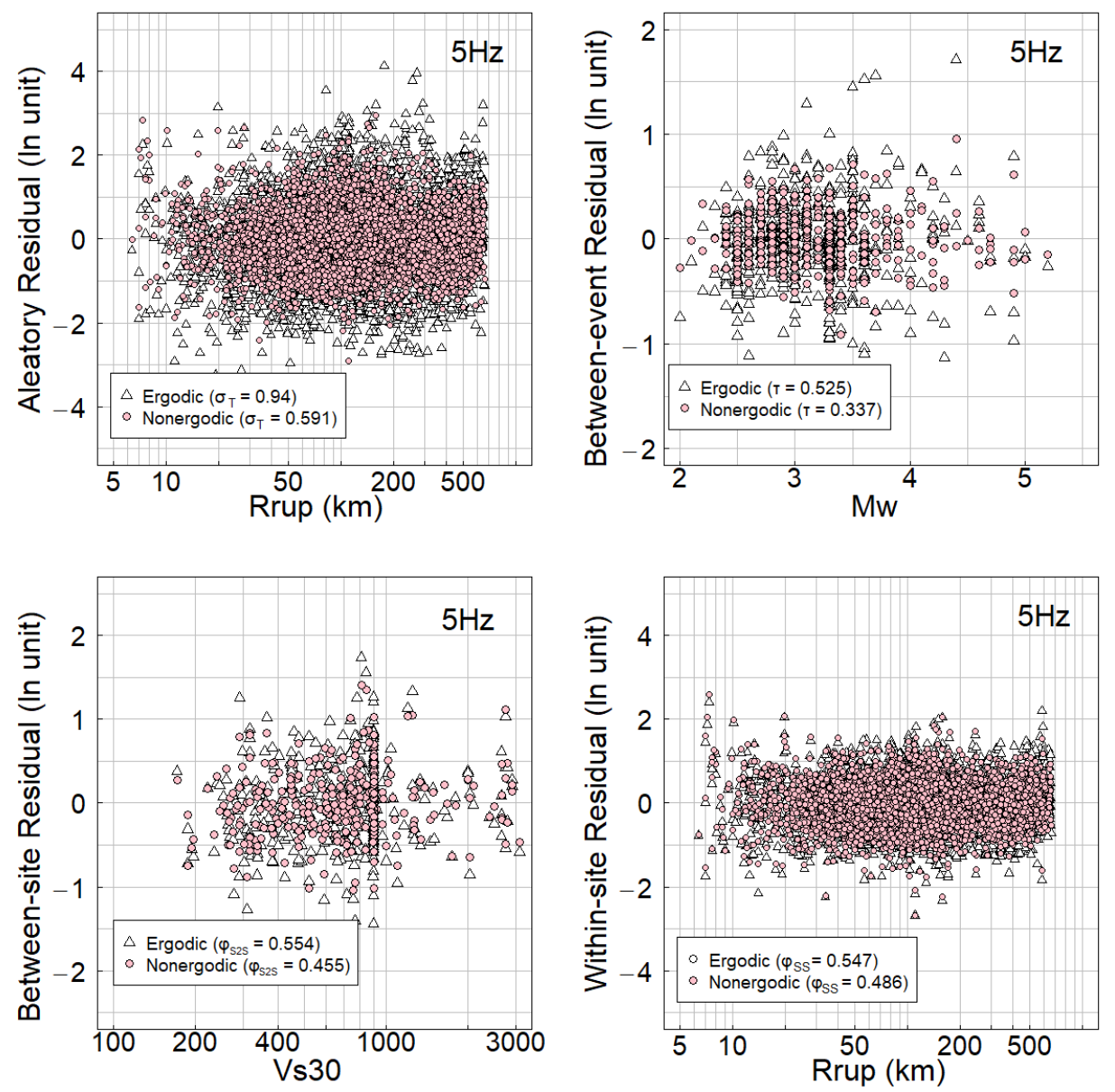

Fig. 6 Residual of the ergodic GMM (triangle) and non-ergodic GMM (circle) for 5.0 Hz. 


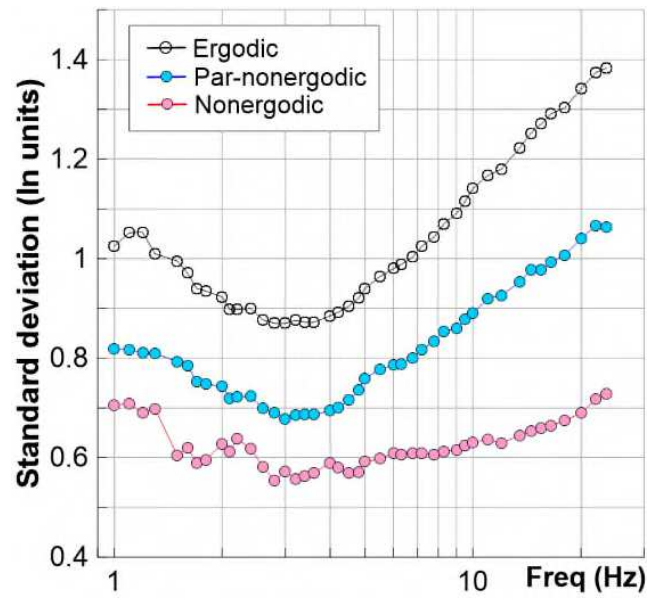

Fig. 7 The aleatory standard deviation of ergodic, partial, and non-ergodic GMMs.

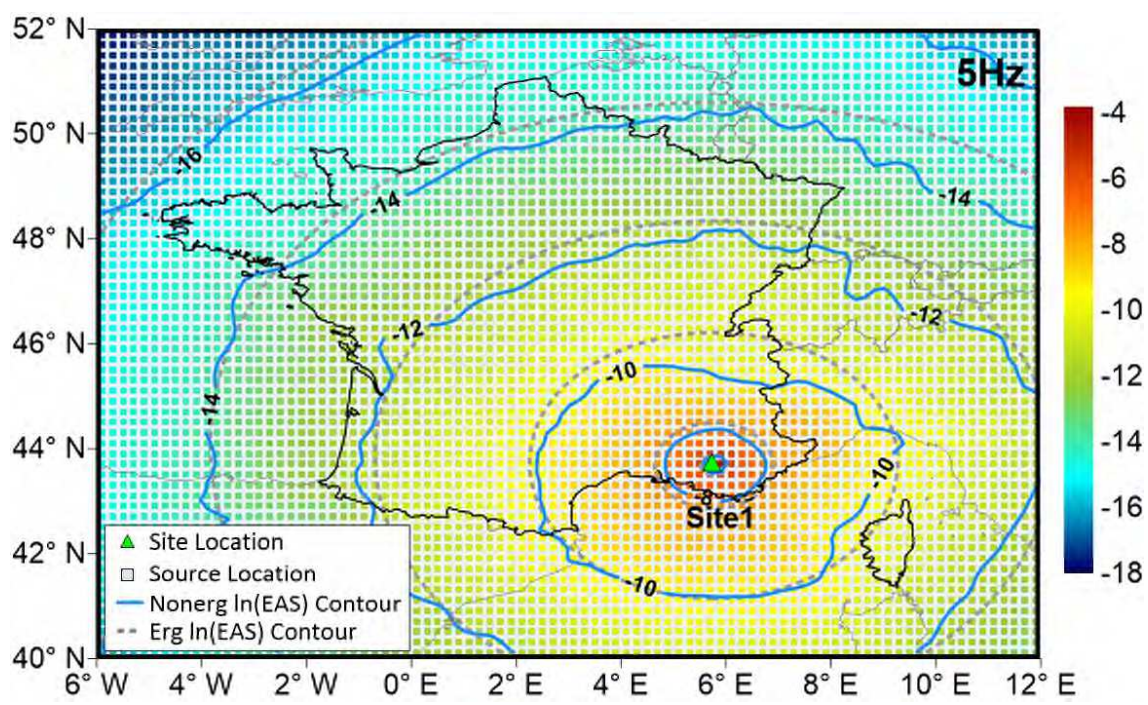

496 Fig. 8 Median EAS predictions at Site1 for the French ergodic model and the non-ergodic model at 5.0 Hz. The squares in the map indicate the source grids ( $0.2 \times 0.2$ degrees), the solid lines mean the contour for the EAS level for non-ergodic model in the natural log units, and the dashed. Lines show the contour for the ergodic model. 

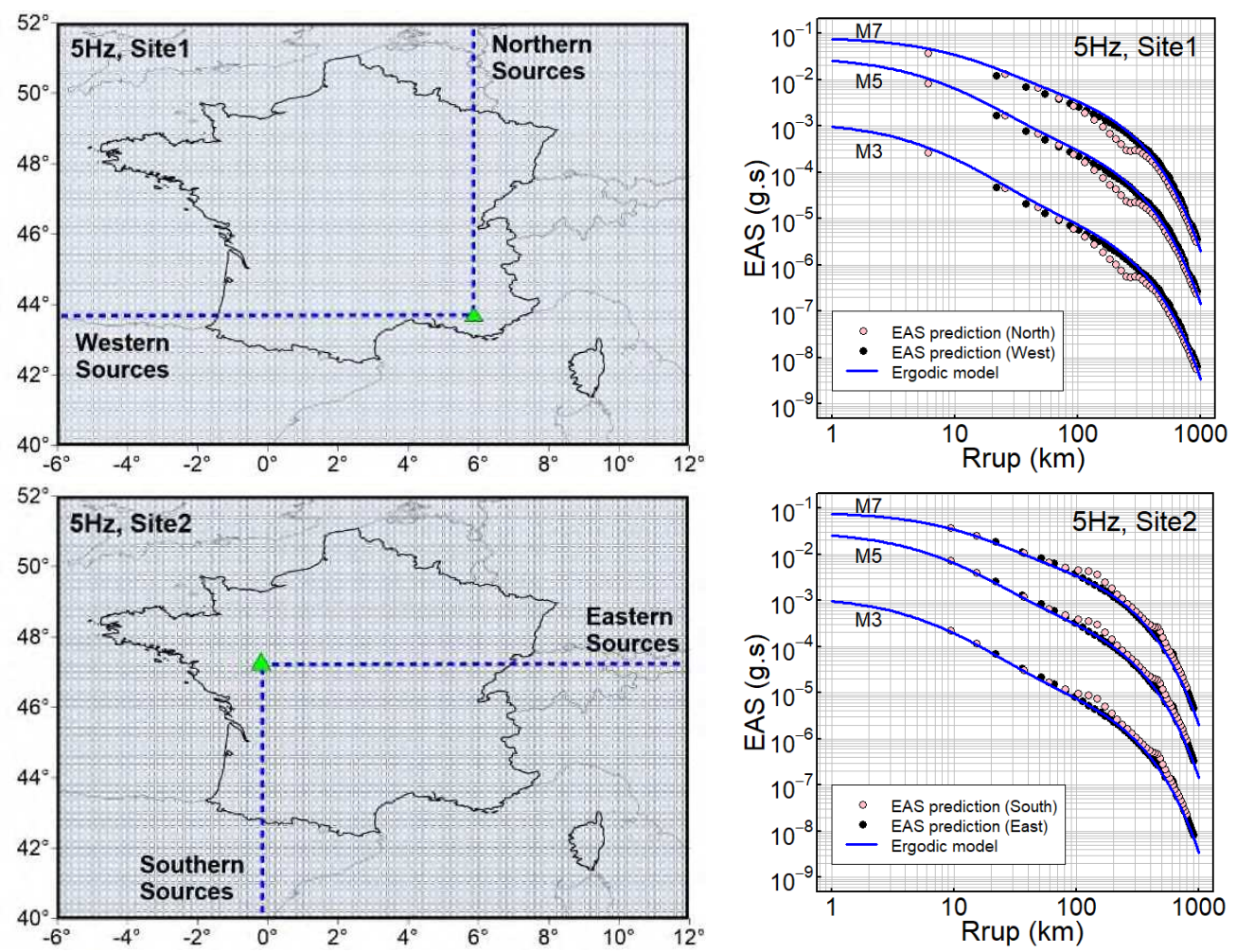

501 Fig. 9 Distance scaling of the EAS prediction of ergodic and non-ergodic models at the given site for $5.0 \mathrm{~Hz}$, for 502 Site1 (Top) and Site2 (Bottom).

503

504
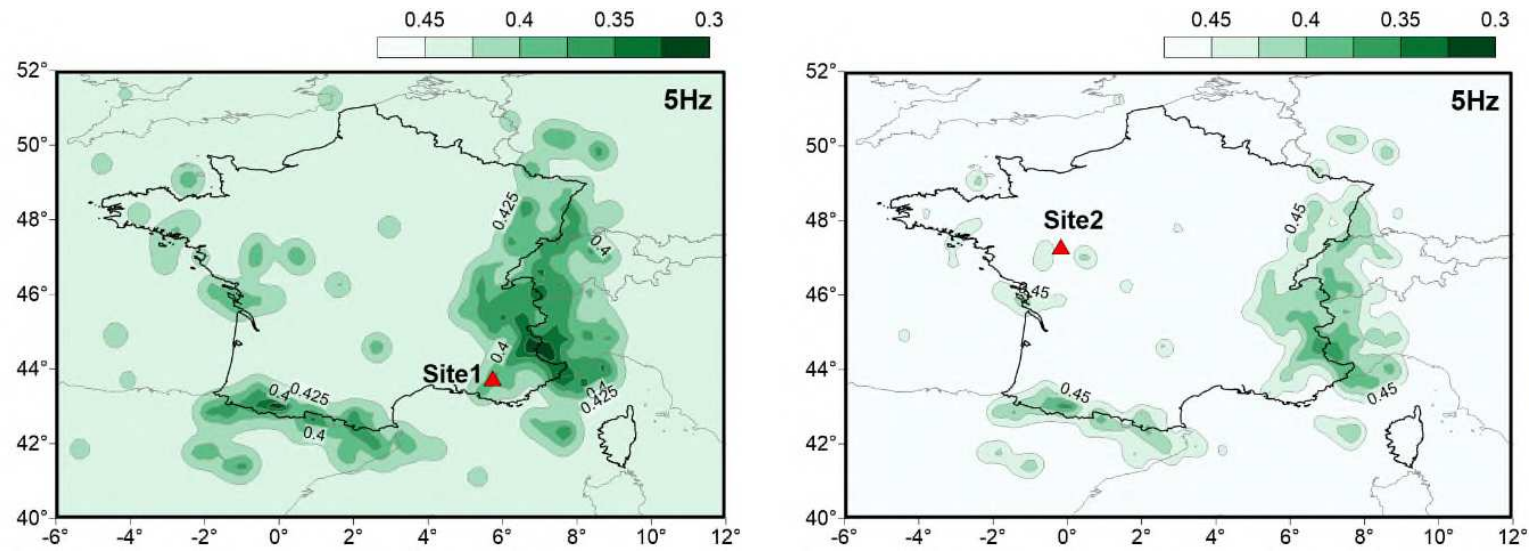

Fig. 10 Epistemic uncertainty of a non-ergodic model per cell at 5.0 Hz for Site1 (Left) and Site2 (Right). 

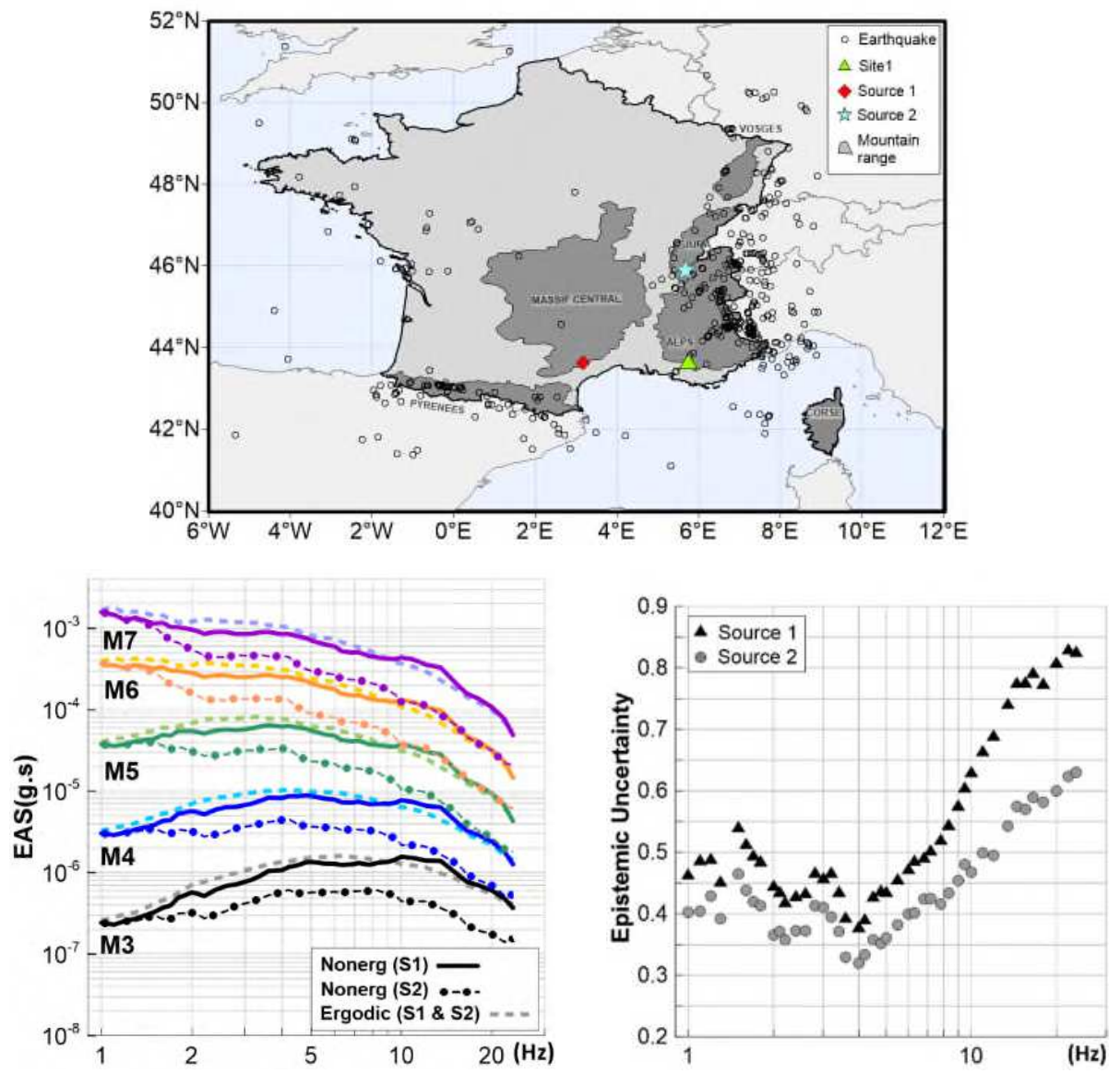

507 Fig 11. Top Two target sources (Source $1,43.7^{\circ} \mathrm{N}, 2.7^{\circ} \mathrm{E}$, Source $2,45.9^{\circ} \mathrm{N}, 5.7^{\circ} \mathrm{E}$ ) is located west and north of 508 Site1 $\left(43.6748^{\circ} \mathrm{N}, 5.7664^{\circ} \mathrm{E}\right)$ at a distance of $246.8 \mathrm{~km}$ and $247 \mathrm{~km}$, respectively. Left bottom Median EAS spectra 509 of ergodic and non-ergodic models from M3 to M7, for Source 1 and Source2. Right bottom Epistemic uncertainty 510 per frequency for Source 1 and Source2.
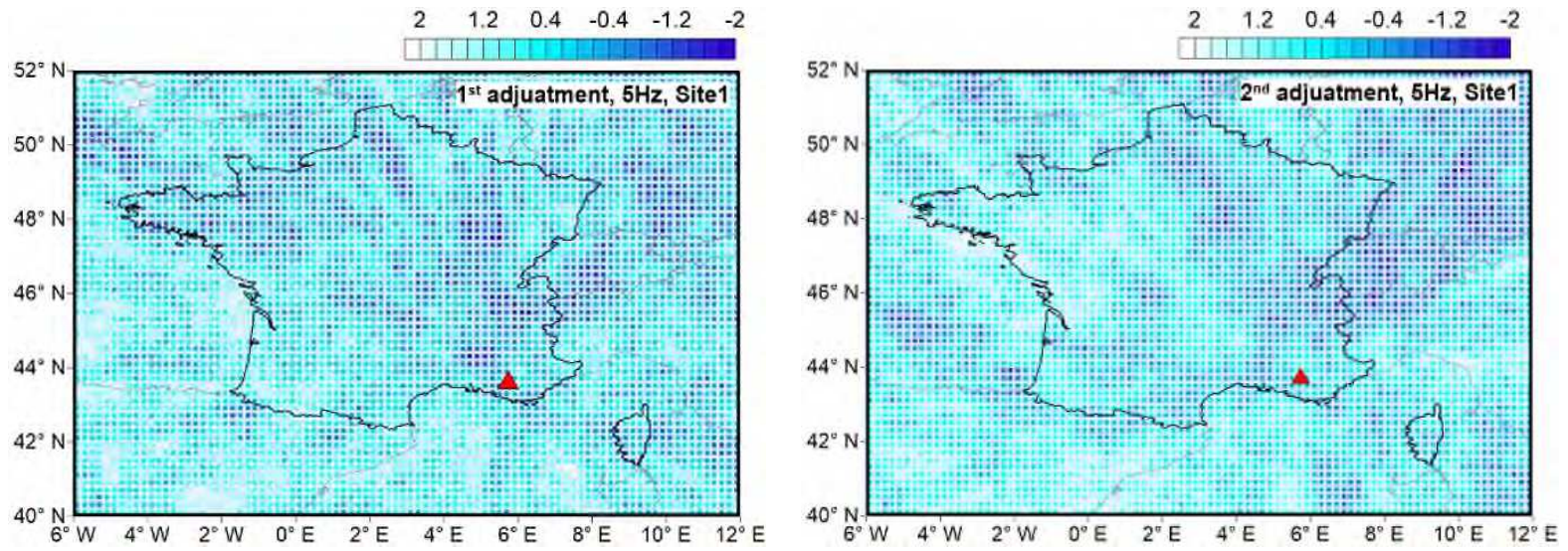

Fig12. Two samples of 100 maps for sampled adjustments for $5 \mathrm{~Hz}$ at Site1. 


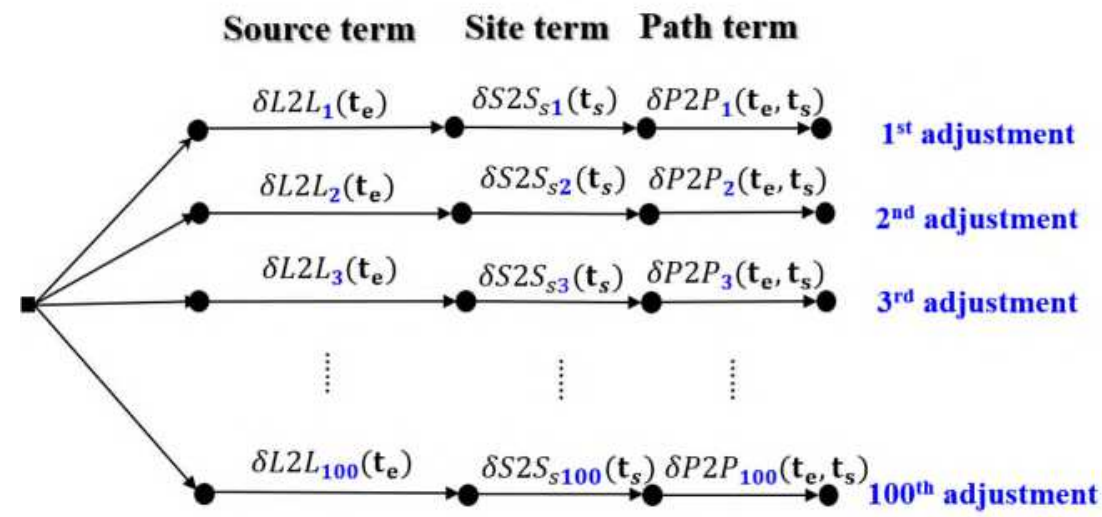

Fig.13 A logic tree with 100 branches of the non-ergodic terms for the GMM.

516
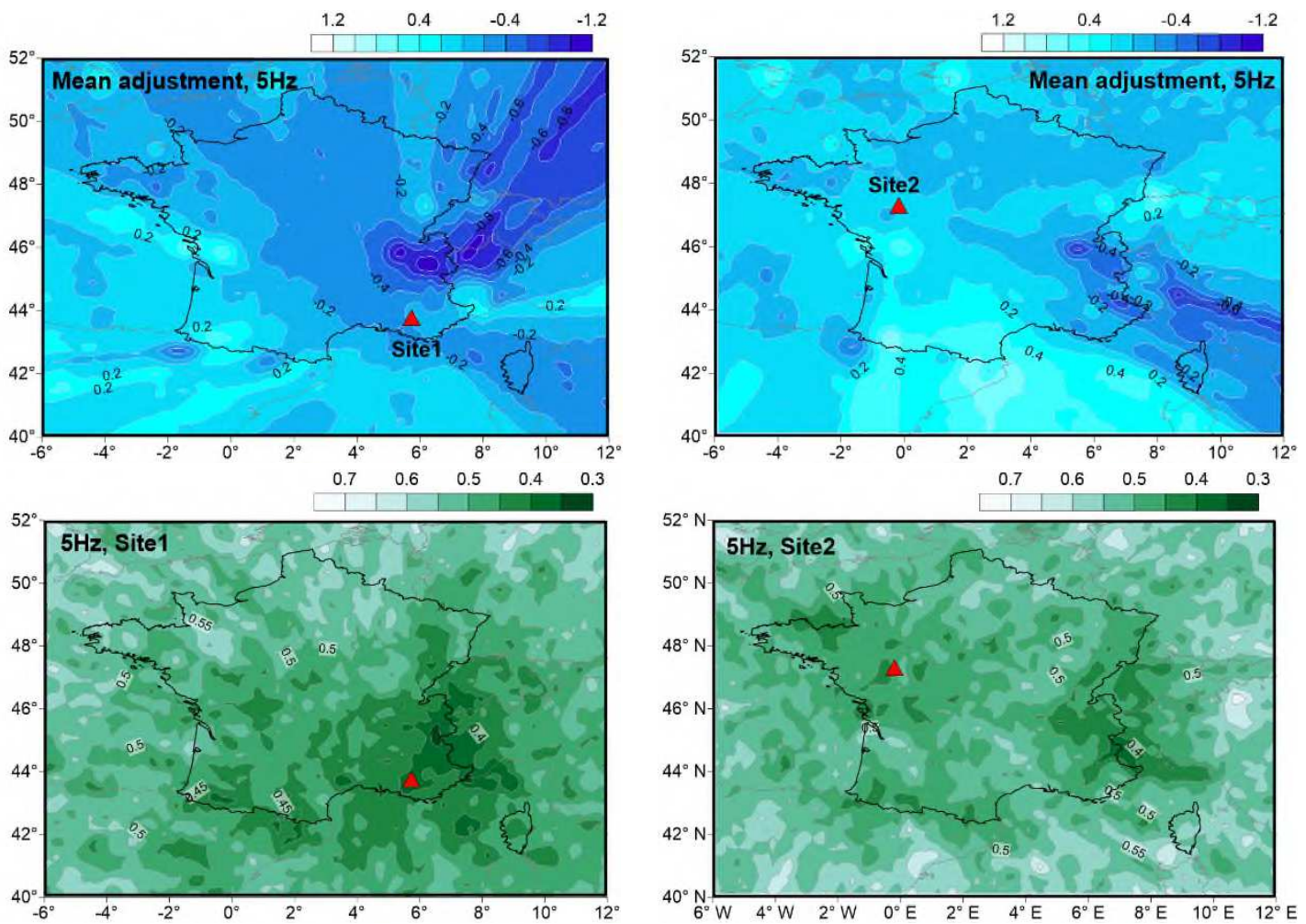

517 Fig.14 Mean and Standard deviation of 100 residuals per cell, which are differences between an ergodic $\ln ($ EAS) 518 and 100 non-ergodic $\ln (\mathrm{EAS})$ at Site1 (Left) and Site2 (Right) for $5.0 \mathrm{~Hz}$. 

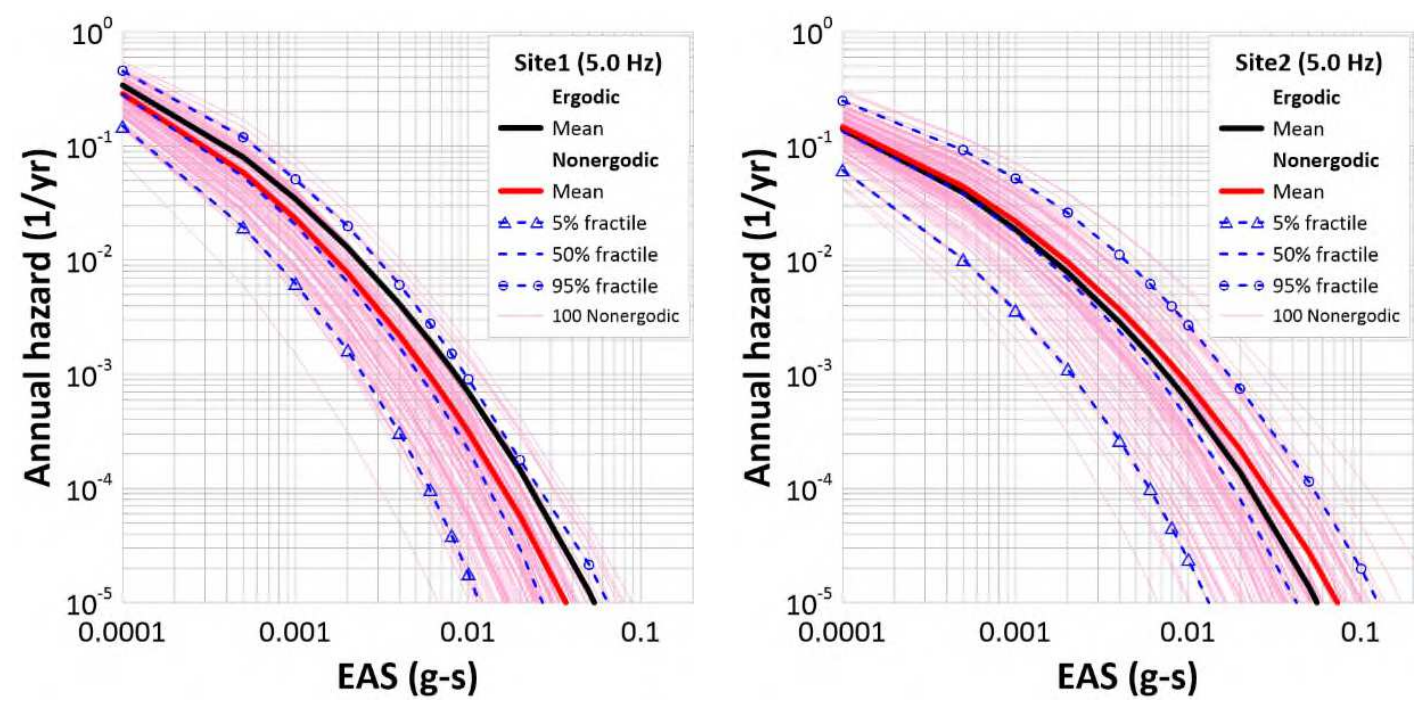

520 Fig. 15 Mean hazard as well as 5\%, 50\%, and 95\% fractiles of the resulting hazard curve distribution for Site1 521 (Left) and Site2 (Right) for $5.0 \mathrm{~Hz}$. 
Table 1 Coefficients for the ergodic EAS model and hyperparameters for the VCM for France

\begin{tabular}{|c|c|c|c|c|c|c|c|c|c|c|c|c|c|c|c|c|c|c|}
\hline \multirow[b]{2}{*}{ Freq } & \multicolumn{12}{|c|}{ Ergodic Coeffecient } & \multicolumn{6}{|c|}{ Hyperparameters } \\
\hline & $\mathbf{c}_{1}$ & $\mathbf{c}_{2}$ & $\mathbf{c}_{3}$ & $\mathbf{c}_{4}$ & $\mathbf{c}_{5}$ & $\mathbf{c}_{6}$ & $\mathbf{c}_{7}$ & $\mathbf{c}_{8}$ & $\mathbf{c}_{9}$ & $\mathbf{c}_{n}$ & $\mathbf{c}_{\mathbf{m}}$ & $\mathbf{c}_{\mathrm{hm}}$ & $\theta_{-1}$ & $\boldsymbol{\theta}_{0}$ & $\boldsymbol{\theta}_{4}$ & $\rho_{-1}$ & $\rho_{0}$ & $\rho_{4}$ \\
\hline 1 & -3.831 & 1.27 & -0.339 & -2.165 & 7.581 & 0.452 & -0.0037 & -1.220 & -0.002 & 3.714 & 5.616 & 3.811 & 0.392 & 0.371 & 0.149 & 0.425 & 0.904 & 0.468 \\
\hline 1.5 & -3.872 & 1.27 & -0.261 & -2.165 & 7.580 & 0.454 & -0.0042 & -1.192 & -0.002 & 4.561 & 5.650 & 3.780 & 0.484 & 0.362 & 0.151 & 0.385 & 1.27 & 0.474 \\
\hline 2 & -4.012 & 1.27 & -0.182 & -2.165 & 7.578 & 0.457 & -0.0047 & -1.163 & 0.0058 & 5.619 & 5.373 & 3.743 & 0.393 & 0.308 & 0.152 & 0.250 & 1.04 & 0.557 \\
\hline 3 & -3.884 & 1.27 & -0.108 & -2.165 & 7.566 & 0.464 & -0.0055 & -1.009 & 0.0122 & 8.292 & 5.247 & 3.653 & 0.387 & 0.288 & 0.150 & 0.234 & 0.256 & 0.474 \\
\hline 4 & -3.858 & 1.27 & -0.069 & -2.165 & 7.544 & 0.470 & -0.0063 & -0.821 & 0.0197 & 11.034 & 5.198 & 3.582 & 0.322 & 0.228 & 0.150 & 0.373 & 0.291 & 0.545 \\
\hline 5 & -4.042 & 1.27 & -0.041 & -2.165 & 7.488 & 0.476 & -0.0072 & -0.699 & 0.0318 & 14.314 & 5.165 & 3.507 & 0.372 & 0.299 & 0.154 & 0.436 & 0.311 & 0.443 \\
\hline 5.5 & -4.061 & 1.27 & -0.037 & -2.165 & 7.462 & 0.477 & -0.0074 & -0.657 & 0.0353 & 15.131 & 5.157 & 3.487 & 0.376 & 0.347 & 0.150 & 0.446 & 0.333 & 0.484 \\
\hline 6 & -4.096 & 1.27 & -0.034 & -2.165 & 7.436 & 0.479 & -0.0075 & -0.638 & 0.0369 & 15.931 & 5.148 & 3.468 & 0.381 & 0.379 & 0.149 & 0.479 & 0.390 & 0.476 \\
\hline 7.2 & -4.288 & 1.27 & -0.026 & -2.165 & 7.2768 & 0.482 & -0.0080 & -0.566 & 0.0473 & 17.911 & 5.117 & 3.396 & 0.407 & 0.461 & 0.150 & 0.443 & 0.423 & 0.578 \\
\hline 8.3 & -4.423 & 1.27 & -0.021 & -2.165 & 7.1352 & 0.484 & -0.0084 & -0.505 & 0.0489 & 18.653 & 5.094 & 3.341 & 0.456 & 0.492 & 0.149 & 0.514 & 0.459 & 0.513 \\
\hline 10 & -4.599 & 1.27 & -0.017 & -2.165 & 6.8004 & 0.486 & -0.0090 & -0.461 & 0.0538 & 18.827 & 5.068 & 3.227 & 0.549 & 0.579 & 0.151 & 0.582 & 0.598 & 0.506 \\
\hline 13.5 & -4.883 & 1.27 & -0.013 & -2.165 & 6.4551 & 0.487 & -0.0100 & -0.367 & 0.0621 & 18.028 & 5.062 & 3.109 & 0.659 & 0.709 & 0.152 & 0.763 & 0.468 & 0.478 \\
\hline 15.5 & -5.095 & 1.27 & -0.010 & -2.165 & 6.4551 & 0.488 & -0.0105 & -0.278 & 0.0650 & 17.588 & 5.060 & 3.106 & 0.683 & 0.728 & 0.151 & 0.833 & 0.400 & 0.503 \\
\hline 18 & -5.288 & 1.27 & -0.009 & -2.165 & 6.4551 & 0.488 & -0.0108 & -0.265 & 0.0606 & 17.174 & 5.059 & 3.103 & 0.701 & 0.752 & 0.149 & 0.957 & 0.423 & 0.508 \\
\hline 20 & -5.515 & 1.27 & -0.006 & -2.165 & 6.4551 & 0.488 & -0.0110 & -0.215 & 0.0646 & 16.959 & 5.059 & 3.102 & 0.732 & 0.752 & 0.148 & 0.933 & 0.427 & 0.469 \\
\hline 23.5 & -5.941 & 1.27 & 0.0018 & -2.165 & 6.4551 & 0.489 & -0.0114 & -0.056 & 0.0600 & 16.3134 & 5.063 & 3.099 & 0.713 & 0.783 & 0.149 & 0.845 & 0.467 & 0.434 \\
\hline
\end{tabular}




\section{Supplementary Files}

This is a list of supplementary files associated with this preprint. Click to download.

- totalresidualadjustment5Hz.xlsx 